\title{
HIPÓCRATES Y LOS ESCRITOS HIPOCRÁTICOS: ORIGEN DE LA MEDICINA CIENTÍFICA
}

\author{
Juan Antonio López Férez \\ U.N.E.D.
}

1. Desde comienzos del siglo VI a.C., los filósofos más conspicuos (Tales de Mileto, Anaximandro, Anaxímenes, Heráclito...) venían estudiando la naturaleza, el cosmos en que el hombre se desenvuelve, al tiempo que examinaban las relaciones entre los hombres, el papel de la religión en la sociedad humana, la función de la ley y la costumbre. Posteriormente, ya en el siglo $v$ las ciudades de la costa de Jonia, ribera occidental de la actual Turquia, siguieron dando excelentes pensadores, aunque la actividad intelectual se extendió por toda la costa mediterránea de habla griega: Demócrito de Abdera, Diógenes de Apolonia, Empédocles de Agrigento, y, sobre todo, Hipócrates y la Escuela médica de Cos son buen ejemplo de ello.

Diógenes de Apolonia, tomando teorias anteriores y refundiéndolas con nuevos postulados, tomaba el aire como elemento primitivo fundamental en el universo, lo que tuvo una clara influencia en varios escritos hipocráticos'.

A su vez, Demócrito, aparte de formular con especial agudeza la teoría atomista, escribió sobre múltiples cuestiones de gran repercusión en la medicina de su época. Notablemente, sus teorias sobre la naturaleza como norma razonable opuesta al azar ${ }^{2}$, sus estudios acerca de la etiología o explicación razonada y causal de todos los hechos ${ }^{3}$, su concepción sobre el hombre al que tiene por «un universo en pequeño (microcosmos)»" su postulado de que el semen procede de todas las partes del cuerpo ${ }^{5}$, sus especulaciones

1 Véase la nueva edición de los fragmentos por A. Laks, Diogène d'Apollonie. La dernière cosmologie présocratique, Lille, 1983.

2 Fr. 176 D. K. Cf. mi artículo, "La idea de phýsis en Demócrito y su utilización en el Corpus Hippocraticum", Cuadernos de Filologia clásica, 8, 1975, págs. 209-218. Para la interrelación de los Presocráticos y la Medicina, consúltese J. S. Lasso de la Vega, «Pensamiento presocrático y medicina", en Historia Universal de la Medicina, ed. P. Laín Entralgo, Madrid, 1972, págs. 317-326.

Frs. 83, 118, 149, 175 y 234.

4 Fr. 34.

${ }^{5}$ Cf. E. Lesky, Die Zeugungs-und Vererbunslehren der Antike und ihr Nachwirken, Wies- 
sobre la salud y la enfermedad tuvieron amplia influencia en algunos escritos hipocráticos, como Sobre la generación y Sobre la naturaleza del niño.

La presencia de Empédocles en la colección hipocrática ${ }^{b}$, y la importancia de los postulados de Anaxágoras entre los médicos ${ }^{7}$ han sido también bien estudiadas. Los sofistas también dejaron numerosas huellas en los planteamientos y esquemas formales de varios tratados hipocráticos ${ }^{8}$. Precisamente, el movimiento sofistico contribuyó poderosamente al surgimiento de varias ciencias, $\mathbf{o}$, al menos, a la revolución cultural que se tradujo en el nacimiento vigoroso de varias parcelas del saber humano con la suficiente independencia como para adquirir verdadero rango científico. Tales ciencias formaron, cada una por sí, un conjunto autónomo de conocimientos que podian ser racionalmente explicados y transmitidos.

Así, pues, en los últimos decenios del siglo $\mathrm{V}$, aparte de los matemáticos, geómetras y astrónomos, que nos han llegado en estado sumamente fragmentario pero suficiente para saber de sus logros, nos encontramos con una Historia que adquiere rango científico gracias al designio de Tucídides, con una Oratoria que estudia de forma racional los sinónimos, el origen del lenguaje y las diferencias entre prosa y poesia; pero, ante todo, nos vemos ante una Medicina racional que sienta las bases de un conocimiento científico.

2. En el terreno médico, a mediados del siglo $\mathrm{v}$ a.C. no servían ya las viejas explicaciones mitológicas sobre la enfermedad y la curación. Por un lado, se decía que el titán Prometeo, al tiempo que enseñaba las letras y los números a los mortales, les dio los primeros conocimientos médicos como si de un primer inventor se tratara ${ }^{9}$. Por otra parte, era Asclepio quien pasaba por ser el mítico fundador de la medicina ${ }^{10}$. Hijo de Apolo, el dios sanador y protector de la Medicina, fue discípulo, según es fama, del centauro Quirón. Sea como fuere, en época histórica hallamos en Grecia varios templos consagrados a Asclepio, y en ellos, con diversas variantes, se trataba de sanar a los enfermos que allí acudian recurriendo a prácticas supersticiosas y mágicas, mientras los pacientes dormían entre sueños relacionados con el dios y con la propia curación. El templo de Epidauro es el más alto exponente de esa medicina teúrgica y divinizada, atendida por una casta sacerdotal

baden, 1950. Cf. nuestro trabajo "Ideas embriológicas de Demócrito", Asclepio 34, 1982, págs ${ }_{6} 317-326$.

6 Cf. J. Jouanna, "Présence d'Empédocle dans la Collection hippocratique», Bull. Assoc. G. Budé, 1961, págs. 451-463.

7 Ver M. Vegetti, «II De locis in homine fra Anassagora ed Ippocrate", Rend. Instituto Lombardo, 99,1965 , págs. 192-213.

${ }_{8} \mathrm{Cf}$. L. Bourgey, Observation et expérience chez les médecins de la Collection hippocratique, Paris, 1953, págs. 47 ss.

9 Esquilo, Prometeo encadenado, 476 ss.

10 Veáse L. Gil, Therapeia. La medicina popular en el mundo clásico, Madrid, 1969, págs. 
de alto prestigio. El santuario de Asclepio en Cos es, según los arqueólogos, de la primera mitad del siglo IV a.C., con lo que resultan infundadas las noticias que querían ver en el padre de Hipócrates, el gran médico que estudiaremos a continuación, una asclepiada del templo de Cos. En verdad, el apelativo «asclepiada» se aplicó, en general, durante el siglo v a.C. a diversas familias y grupos profesionales íntimamente relacionados con la práctica de la medicina y que pretendian, de algún modo, hacer remontar hasta Asclepio sus facultades curativas.

Por lo demás, durante todo el período arcaico griego, la enfermedad es entendida como resultado de un castigo divino en pago a los extravíos y pecados cometidos por el propio enfermo o por sus padres o antepasados, cuando no se la consideraba simple producto de la envidia divina ante el excesivo encumbramiento de un humano.

3. Por diversas noticias " sabemos que durante el siglo $v$ a.C. se fueron formando y adquirieron gran prestigio varias Escuelas médicas situadas, respectivamente, en Cos (pequeña isla cercana a la actual Turquía, justo al Noroeste de Rodas), Cnido (en el extremo de una larga península sita al sur de Cos), Crotona (al Sur de Italia) y Cirene (al Norte de la actual Libia). Precisamente, a la Escuela de Cos pertenece Hipócrates, que siempre ha sido considerado el padre de la medicina científica europea. Sobre la vida del eximio médico tenemos pocos datos biográficos dignos de crédito, pues proceden en su mayoría de biógrafos tardíos, algunos de ellos médicos también, no anteriores al siglo II d.C.

Hipócrates ${ }^{12}$ nació hacia el 460 a.C. en la isla griega de Cos, hijo de Heraclides, médico también. En la formación de Hipócrates influyeron, aparte de su padre y del ambiente en que se crió, algunos filósofos y sofistas ilustres del momento. Quiere una vieja tradición que Demócrito fuera su maestro, o en todo caso amigo íntimo. También nos hablan las fuentes de un estrecho contacto de Hipócrates con Gorgias, ilustre sofista y verdadero

351-399, concretamiente los apartados «ensueño y medicina», «la incubatio», «la terapia onírica" y "los milagros de Asclepio".

11 Heródoto, III, 131. Ver además Galeno, X, 5 (Kühn).

12 Sobre la figura histórica de Hipócrates hay una bibliografia inmensa. En español contamos con los trabajos de P. Laín Entralgo, La medicina hipocrática, Madrid, 1970 (reim. 1983); "La medicina hipocrática», en Historia universal de la Medicina, ed. P. Laín Entralgo, págs. 73-117. Véase también R. Joly, "Hippocrates of Cos", en Dictionnary of scientific Biography, Nueva York, 1972, págs. 418-431; E. D. Phillips, Greek Medicine, Londres, 1973. Muy recomendable sobre Hipócrates, la medicina hipocrática y la transmisión de tal medicina son: el libro de Bourgey citado en nota 8; H. Flaschar (ed), Antike Medizin, Darmstadt, 1971; R. Joly, Le niveau de la science hippocratique, Paris, 1965; W. D. Smith, The hippocratic Tradition, Ithaca-Londres, 1979.

El lector interesado puede acudir al repertorio completo de G. Maloney-R. Savoie, Cinq cents ans de bibliographie hippocratique, Quebec, 1982, donde se recoge todo lo importante publicado entre 1473 y 1982. 
maestro del arte retórico. Además entre los mentores del gran médico figura Heródico de Selimbria, famoso porque curaba las enfermedades a fuerza de dieta y ejercicios gimnásticos.

Encontramos bastantes noticias de Hipócrates en los diálogos de Plató $^{13}, y$, asimismo, en las obras de Aristóteles ${ }^{14}$; con tales testimonios habría material más que suficiente para tener al médico que estudiamos como el más eximio de su época y de trascendental importancia en los siglos posteriores. Otros datos biográficos nos lo suministran la Suda, léxico compuesto hacia el siglo $\mathrm{X}$ de nuestra era; una Vida poco de fiar, atribuida a Sorano; las obras de Galeno; etc.

Un documento de especial relevancia es el Anonymus Londinensis, papiro del siglo Il d.C. encontrado en 1892 , en donde se conservan varios fragmentos de la Historia de la Medicina escrita por Menón, discípulo de Aristóteles. Entre los varios médicos y teorías citados en tal texto papiráceo sobresale Hipócrates, si bien dentro de un contexto confuso y debatido, en el que cabe ver no pocas teorías y postulados posteriores a nuestro autor.

Sabemos que Hipócrates viajó bastante y ejerció la medicina en diversos puntos de Grecia. Murió con más de ochenta años y su sepulcro era mostrado en Larisa (Tesalia) a turistas y visitantes hasta bien entrado el periodo romano.

4. Casi todos los estudiosos de la Historia de la Medicina y de la Literatura griega están conformes en aceptar la decisiva importancia de Hipócrates en el nacimiento de la medicina científica europea, pero, en cambio, no logran ponerse de acuerdo, ni mucho menos, respecto de qué libros fueron escritos por aquél. Además, si examinamos detenidamente dos testimonios importantes, a saber, el Fedro de Platón ${ }^{15}$ y el Anonymus Londinensis ${ }^{16}$, ya mencionado, fundamentales para conocer, respectivamente, la postura de Hipócrates en punto a la naturaleza del todo y a la naturaleza del hombre, $y$ respecto a la función de las phŷsai, o flatos, en el origen y curso de las enfermedades, llegamos a la conclusión de que faitan pruebas irrefragables en cuanto al método exacto seguido por nuestro médico en su quehacer profe-

13 Especialmente en Fedro y Protágoras.

14 Singularmente en la Politica.

15 Cf. R. Joly, «La question hippocratique et le témoignage du Phèdre», Rev. Et. Grecques, 74, 1961, págs. 69-92.

16 Editado y traducido por W. H. S. Jones, The medical writing of Anonymus Londinensis, Cambridge, 1947. Puede acudirse, asimismo a la Introducción general de C. García Gual en Tratados hipocráticos, I, Madrid, 1983, págs. 31 y 38 especialmente. En tal volumen aparecen las traducciones, con notas e introducciones de Sobre la ciencia médica, Sobre el médico, El Pronóstico, Sobre la enfermedad sagrada, por C. García Gual; Juramento, Ley, Sobre la medicina antigua y Sobre la decencia, por M.'D. Lara Nava; Aforismos y Preceptos, por J. A. López Férez, y Sobre la dieta en las enfermedades agudas, por B. Cabellos Alvarez. De tal libro cito más adelante algunas traducciones de pasajes concretos. 
sional. Ante tanto desconcierto, no es de extrañar que en nuestro siglo alguien negara la existencia de libro alguno atribuible a la mano de Hipócrates $^{17}$.

No obstante lo dicho, la opinión más extendida es la que sostiene que un pequeño número de tratados (Pronóstico, Sobre las articulaciones, Sobre las fracturas, Epidemias I y II, Sobre la dieta en las enfermedades agudas y algunas secciones de los Aforismos) es atribuible a Hipócrates, o, al menos, merece ser tenido por estrictamente hipocrático en su contenido y desarrollo.

Realmente el problema de qué escribió propiamente Hipócrates es bastante antiguo. Ya entre los primeros comentaristas de las obras hipocráticas, tal como recoge Galeno en el siglo II d.C., surgió la pregunta de qué tratados eran hipocráticos y cuáles no, partiendo de principios y teorías de escuelas médicas más bien que de criterios filológicos bien fundamentados. Recordemos que en la Escuela de Cos los libros circulaban sin nombre de autor, quizás porque todos y cada uno sabian lo que era de Hipócrates o de alguno de sus discipulos.

5. Se llama Corpus Hippocraticum a unos cincuenta y tres tratados de contenido esencialmente médico que nos han llegado atribuidos a Hipócrates y a su Escuela desde la antigüedad. La edición de E. Littré ${ }^{18}$ sigue siendo la más completa. Muchos tratados particulares han sido estudiados, editados y comentados en los últimos decenios, superando en ocasiones el texto y comentarios ofrecidos por Littré, pero para bastantes escritos es la única fuente filológica digna de mención.

El Corpus Hippocraticum es la primera colección de textos cientificos que nos ha transmitido la antigüedad clásica. La mayoría de sus tratados fue escrita aproximadamente entre los años 420 y 350 a.C. Aún así, tenemos algunos títulos, como Sobre la decencia y Preceptos, que pueden retrotraerse hasta los siglos I o II d.C., por razones de lengua y contenido. Ahora bien, los tratados más destacados de la Colección hipocrática fueron escritos en unos años que coinciden con el período vital de Hipócrates, razón que nos induce a sostener, como hiciera desde siempre la tradición y viene siendo defendido por grandes filólogos y estudiosos de la Historia de la Medicina, que algunos de ellos muy bien pudieron ser escritos por el gran médico o por algunos de sus discípulos más directos. Pero, cuando decimos «tratados, escritos u obras hipocráticas", no queremos decir que hayan sido escritos por el propio Hipócrates, pues, como adelantábamos, no estamos seguros en nin-

17 L. Edelstein, «The genuine works of Hippocrates», Bull. Hist. Medicine, 7, 1939, págs. 236-248. Recogido luego en Ancient Medicine, Ed. O. y C. L. Temkim, Baltimore, 1967, págs. 133-144.

18 E. Littré, Oeuvres complètes d'Hippocrate, I-IX París, 1839-1861 (Repr. Amsterdam, 1961). Tal obra se impuso sobre la edición de F. Z. Ermerins, Hippocratis et aliorum medicorum veterum reliquiae, I-III, Leipzig-Paris, 1859-1864. 
gún caso de que una obra determinada haya sido compuesta por Hipócrates en persona. Casi todos los tratados de que venimos hablando proceden de la Biblioteca de Cos, es decir, la que constituía el precioso patrimonio de los Asclepiadas de tal lugar, celosamente guardada y transmitida de padres a hijos. En tal Biblioteca familiar la noción de autor resultaba bastante difuminada, mientras que los retoques, añadidos y comentarios marginales debian de ser cosa harto frecuente.

A los escritos hipocráticos, es decir, los atribuibles a Hipócrates y a su círculo de colaboradores y discípulos más cercanos, se fueron añadiendo en época tardía, a fines del pasado milenio y durante los primeros siglos del nuestro, algunos tratados más de contenido médico diverso, pero influidos, en mayor o menor medida, por teorías filosóficas helenísticas, fundamentalmente epicúreas y estoicas. Así, la Colección se fue engrosando paulatinamente, y se constituyó, al tiempo, un Corpus cerrado en torno al siglo $\mathrm{X}$ d.C., en Bizancio. Conservamos dos códices hipocráticos del siglo $\times$ d.C.: Laurentianus 74,7(B) y Marcianus Graecus $269(M)$. Nos han llegado, asimismo, espléndidos manuscritos de los siglos XI y XII y otros muchos posteriores $^{39}$.

6. Al examinar una lista de las obras hipocrática nos sorprende la diversidad temática ${ }^{20}$ :

a) Escritos de carácter general (Juramento, Ley, Sobre la medicina antigua...)

b) Escritos de contenido anatómico y fisiológico (Sobre la anatomia, Sobre el corazón, Sobre las carnes, Sobre la generación, Sobre la naturaleza del niño...)

c) Escritos dietéticos (Sobre la dieta, Sobre la dieta sana)

d) Escritos de patología general (Sobre los aires, aguas y lugares, Sobre los humores, Sobre los flatos, Pronóstico, Predicciones I y II, Prenociones de Cos...)

e) Escritos de patología especial (Epidemias I-VII, Sobre las afecciones, Sobre las enfermedades I-III, Sobre la enfermedad sagrada...)

f) Escritos terapéuticos (Sobre la dieta en las enfermedades agudas...)

g) Escritos quirúrgicos (Sobre las articulaciones, Sobre las fracturas, Sobre la palanca, Sobre las hemorroides, Sobre las heridas en la cabeza...)

h) Escritos oftalmológicos (Sobre la visión)

i) Escritos ginecológicos, obstétricos y pediátricos (Sobre las doncellas, Sobre la naturaleza de la mujer, Sobre las enfermedades de la mujer, Sobre el parto de siete meses, Sobre la dentición...)

${ }^{19}$ Cf. J. Irigoin, "Tradition manuscrite et histoire du Texte. Quelques problèmes relatifs à la Collection hippocratique", en La Collection Hippocratique et son rôle dans I'histoire de la médecine, (Colloque de Strasbourg Octobre, 1972), Leiden, 1975, págs. 3-18.

20 Cf. P. Laín Entralgo, La medicina hipocrática, págs. 391-421. 
Ya el simple estudio de una colección tan diversa desde el punto de vista del contenido plantea numerosas dificultades a causa del carácter tan heterogéneo de los tratados que comprende. Pero, si dejamos al margen este aspecto, nos encaramos con otro no menos dificil de sortear y vencer: el referente a la cronologia absoluta y relativa de los distintos escritos, punto al que hemos apuntado ligeramente y en el que no vamos a insistir por la enorme dificultad que encierra y por tratarse de un problema abierto en casi su totalidad. Otra cuestión de interés es a qué Escuela pertenecen los tratados, pues desde hace más de un siglo se viene diciendo que dentro de la Colección hipocrática hay dos grandes grupos de tratados claramente diferenciados entre sí por su orientación doctrinal o de Escuela. De un lado, los tratados cnidios, relacionados con la Escuela de Cnido, caracterizados por una gran artificiosidad en la nosografia o descripción de las enfermedades, recargados de largas listas de enfermedades y atentos más bien a enumerar largos y complicados catálogos de enfermedades que a atender a los enfermos. Sobre las enfermedades II, Sobre las afecciones internas, Sobre las enfermedades de la mujer, Sobre la generación, Sobre la naturaleza del niño, Sobre las enfermedades IV,... pertenecerían a esta línea médica ${ }^{21}$. Destacan por la monotonía en el régimen de vida prescrito, por la exageración desde el punto de vista descriptivo y por la gran sumisión a los datos sin demasiado espíritu crítico. De otra parte, los escritos coicos, o propios de Cos, conspicuos por ofrecer una descripción técnica que atiende más al enfermo que a la enfermedad, o sea, donde prevalece la patografia sobre la nosografia. En ellos se observan con especial cuidado los signos (sẽmeîa) a fin de obtener pruebas objetivas (tekméria); la búsqueda del momento propicio (kairós) es otro rasgo distintivo; asimismo, la presencia de la teoria humoral, normalmente con cuatro humores. Todas las obras atribuidas a Hipócrates y que antes mencionábamos entran en este grupo, aparte de algunas otras.

No obstante quedaba un grupo de tratados que no entraba bien en ninguno de esos grupos (Sobre la dieta sana, Sobre la ciencia médica, Sobre las afecciones) por compartir postulados de ambos.

Ahora bien, en los últimos años se viene observando que no hay suficientes razones para dividir tajantemente en dos grupos los escritos hipocráticos a partir del contenido de los mismos, sino que teorías y postulados tenidos por eminentemente coicos se encuentran también en tratados considerados cnidios, y viceversa. En resumidas cuentas, son muchas más las teorias, principios generales y métodos que unen a los escritos hipocráticos que los postulados que permiten diferenciarlos ${ }^{22}$. Abordando los tratados hipocráticos con nuevos criterios de contenido, en estricta dependencia de los saberes y teorías de aquellos momentos, resulta que una serie de escri-

21 Cf. L. Bourgey, Observation..., págs. 41 y ss.

22 Cf. A. Thivel, Cnide et Cos? Essai sur les doctrines médicales dans la Collection hippocratique, Paris, 1981. Acúdase también a J. Jouanna, Hippocrate et l'école de Cnide, Paris, 1974 y H. Grensemann. Knidische Medizin, I, Berlín-N. York, 1975. 
tos ofrece la teoría de los contrarios, el pronóstico, la digestión concebida como resultado de una cocción, la idea de los días críticos, la doctrina de las estaciones del año y las edades de la vida en relación íntima con la práctica médica y el decurso de las enfermedades, es decir, principios que tienen un marcado carácter antiguo, de claro sabor jonio. Frente a ellos, otros tratados dan crédito a los principios pneumáticos, en los que luego insistiremos, a la teoría de los semejantes, al tiempo que se tiene a la digestión como producto de la putrefacción de los alimentos ingeridos. Estos últimos escritos estarían relacionados con teorías formuladas por Empédocles, los Eléatas y los Pitagóricos.

7. Vamos a revisar algunas teorias y postulados generales de los tratados hipocráticos saltando por encima de una rigurosa división en escuelas médicas, toda vez que es cada día más aceptada la opinión de que no es metodológicamente aceptable la tajante partición a que aludíamos. En cambio, conviene partir de la afirmación, casi unánimente compartida por los especialistas, de que la medicina hipocrática no habría conseguido el rango de ciencia sin el precedente de la Filosofia presocrática, tan atenta a las relaciones del hombre con el medio ambiente en que se desenvuelve. Siempre es difícil, empero, y no poco arriesgado afirmar que un tratado concreto muestra una influencia directa de determinado filósofo contemporáneo. Más rentable y acertado es pensar que el autor, o autores hipocráticos, estaba al tanto de lucubraciones y postulados filosóficos entonces en boga. En verdad, a lo que sabemos por diversos estudios filológicos, tanto Hipócrates como el círculo de médicos de su escuela estaban al corriente del pensamiento innovador, racional, que venía desarrollándose en Jonia desde finales del siglo vi a. C. y, especialmente, en la primera mitad del siglo $v$ a. C. Dentro de los escritos hipocráticos de fines del siglo $\mathrm{V}$ a. C. y comienzos del IV aparece entablada una gran pugna dialéctica entre quienes sostienen que sin filosofia no hay medicina posible (Sobre la dieta, Sobre los flatos, Sobre los lugares en el hombre...) y los que propugnan, altaneramente, que sin medicina no hay filosofia, 0 , de otro modo, que a la medicina no le hace falta alguna la filosofia para poder desarrollarse plenamente (Sobre la medicina antigua. Sobre la ciencia médica).

Dentro de los tratados médicos hallamos pasajes extremadamente interesantes para comprobar el elevado sentido de la observación y la meticulosidad con que el médico ejercía sus funciones. En el debate siempre abierto entre la razón y la sensación el médico hipocrático se inclina por lo que le dictan sus sentidos, pero sin olvidar la importancia del razonamiento. Aunque es mucho lo que les deben a los filósofos, se oponen a ellos en teorías particulares, en métodos y objetivos; a diferencia del filósofo puro, el médico procura unir siempre la teoría y la práctica.

$Y$ bien, prescindienco de las diatribas doctrinales, $\tan$ fecundas en ocasiones, insistamos en algunos de esos postulados que van a conferir a la medicina el rango de ciencia por su espíritu positivo. 
a) La idea de kósmos, es decir, el "mundo", "universo", "orden", había sido bien desarrollada por los filósofos jonios del siglo VI a. C., y en el v Demócrito sostuvo que el hombre es un microcosmos. En el tratado hipocrático Sobre las semanas leemos que al firmamento le corresponde la piel humana; al aire, el pneuma; al agua, el vientre; a las estrellas el sol, el calor subcutáneo; a la luna, el diafragma; etc. Esta idea de la estrecha relación del hombre con respecto al mundo cósmico exterior está muy difundida dentro de los escritos médicos. Nos hemos ocupado de seguir la pista a esa teoría de la relación e influencia ejercida sobre el hombre por los elementos naturales que le rodean (astros, tierra, clima, estaciones del año, aguas, vientos,...) dentro de los siete libros de las Epidemias ${ }^{23}$. Por otro lado, el tratado Sobre los aires, aguas y lugares está íntegramente consagrado a examinar la profunda interrelación del hombre con el medio ambiente. En la introducción de tal escrito leemos que el médico que se precie de serlo ha de conocer las estaciones del año, vientos, propiedades de las aguas, situación de cada ciudad, momento de la puesta y salida de ciertas constelaciones, etc., en la idea de que según sean la orientación, vientos y aguas, así les irá a las personas de constituciones distintas en un lugar determinado, y de que, atendiendo a tales peculiaridades, habrán de tomarse las oportunas medidas terapéuticas.

b) La naturaleza (physis) es posiblemente el concepto fundamental sobre el que gravita la medicina racional y cientifica en su estadio fundacional. Varios tratados hipocráticos se titulan Sobre la naturaleza (del niño, del hombre, de la mujer...). Entre los Presocráticos abundan los estudios en esa dirección, aunque nos hayan llegado en estado muy fragmentario. No obstante, dichos filósofos habían descubierto la existencia de una "naturaleza» universal, junto a la cual se da la naturaleza particular de cada persona, que viene a ser la constitución de cada ser. Esa "naturaleza» entre los médicos hipocráticos de vanguardia es armónica, ordenada y regular: es justa en sus realizaciones, no arbitraria. El médico que trata una enfermedad o cura un hueso dislocado o fracturado está ayudando a la naturaleza, a la fuerza natural creadora, que por justicia y norma tiende al estado de salud. Esa naturaleza es razonable, es decir, puede comprenderse mediante las luces de nuestra razón, sin necesidad de acudir a ninguna explicación sobrenatural ni divina.

La naturaleza está en consonancia con la ley (nómos), pero puede llegar un momento en que la costumbre se convierta en naturaleza. Precisamente se ha insistido en los últimos años en que dos de los tratados hipocráticos más relevantes (Sobre los aires, aguas y lugares y Sobre la enfermedad sagrada) pudieran ser del mismo autor porque ambos guardan la misma actitud ante la relación de la naturaleza y la norma (phýsis-nómos) ${ }^{24}$. Hablando de

23 J. A. López Férez, "La médecine météorologique et les Epidemies», Actas del Cinquième Colloque international Hippocratique, Berlin, 1984, en prensa.

${ }^{24}$ Cf. H. Grensemann, Die hippokratique Schrift Ueber die heilige Krankheit, Berlin, 1968. 
los macrocéfalos, pueblo situado quizá cerca del Cáucaso y dotado de cabezas enormemente alargadas, el agudo médico y escritor del primero de los mencionados escritos dice que la verdadera razón de tamaña deformación es que a tales gentes, cuando son niños aún, les modelan la cabeza con las manos y la obligan a ser alargada, pero que llegó un momento en que tal rasgo diferenciador, producto de la costumbre, se convirtió en naturaleza y se transmitía a la descendencia.

La naturaleza es también la disposición natural, la condición que nos viene dada desde nuestro nacimiento. En este terreno el médico hipocrático es un avanzado de su época, pues sostiene que no basta con la condición natural para llegar a ser un buen médico, sino que es precisa la enseñanza, el aprendizaje desde la infancia, el esfuerzo y el tiempo ${ }^{25}$.

La naturaleza es también la conformación y modo de ser de la enfermedad. Refiriéndose a la llamada por otros enfermedad sagrada, el autor hipocrático sostiene que en nada le parece que tal afección sea más divina ni más sagrada que las otras, sino que tiene su naturaleza propia, tal como las demás enfermedades ${ }^{26}$.

En Sobre los aires, aguas y lugares ${ }^{27}$ hallamos el mismo espíritu positivo y racional, esencial para sentar las bases de una medicina científica. Refieriéndose a que los escitas le echan la culpa de su impotencia a la divinidad nos dice el tratadista: «sin embargo, personalmente, me parece que esa afección es divina como todas las demás, y que ninguna es ni más divina ni más humana que otra, sino que todas son parecidas y todas divinas. Cada una tiene su propia naturaleza y ninguna acontece sin causa natural».

A la firme idea de que todo parte de la naturaleza y de que nada hay fuera de ésta va ligada la crítica de lo divino ${ }^{28}$. Volviendo a la citada enfermedad considerada hasta entonces sagrada, el perspicaz médico nos dice que esa enfermedad no le parece más divina que las demás, sino que tiene su naturaleza como las demás enfermedades, "y en cuanto a su causa natural, resulta ella divina por lo mismo que lo son todas las demás». Dado que tal afección ataca «a los flemáticos pero no a los biliosos», si fuera más divina que las demás sería preciso que esta enfermedad se presentase por igual en todos, y que no discriminara entre el tipo bilioso y el flemático ${ }^{29}$.

c) La noción de causa, tan importante dentro de la Colección hipocrática, se remonta especialmente a Demócrito, que insistió una y otra vez en dar una razón causal y satisfactoria de los fenómenos visibles ${ }^{30}$. Para él todo

25 Sobre los aires, aguas y lugares, 14, para lo anterior. Ahora hablamos de Ley 2 .

26 Sobre la enfermedad sagrada, 1 Cf. también cap. 5 .

27 Cap. 22, donde la idea aparece dos veces consecutivas.

28 Cf. A. Thivel, «Le "divin" dans la Collection hippocratique» en, La Collection (ver nota 19) págs. 57-76.

29 SQbre la enfermedad sagrada, 5. Ver, asimismo, cap. 21.

$30 \mathrm{Fr} .118$, donde leemos que Demócrito «prefería descubrir una etiología (es decir, una justificación causal) a poseer el reino de los persas". 
tiene su causa, nada sucede al azar, pero los hombres, en su ignorancia, culpan al azar de sus desgracias y adversidades.

La misma teoría de que todo tiene una explicación racional aparece repetidas veces en la Colección hipocrática, especialmente bajo los términos aitia "causa general" y próphasis «causa particular». El tratado Sobre la enfermendad sagrada es fundamental para estudiar la noción de causa ${ }^{31}$. Se critica allí con argumentos demoledores a los charlatanes, purificadores y encantadores que pretendian curar tal afección por medios irracionales y supersticiosos. El autor cree en la uniformidad de la naturaleza, en la regularidad de las causas naturales. La naturaleza conlleva una regularidad absoluta en la correspondencia entre la causa y el efecto, y, por ello, las enfermedades, como todo lo que es natural, tienen determinadas causas y efectos. Todas son divinas, todas son humanas, todas son naturales, todas son explicables racionalmente.

d) Concepto siempre presente en los escritos hipocráticos es el de téchnê,, para el que no tenemos en nuestra lengua un concepto apropiado si queremos abarcarlo en toda su extensión. Se le ha traducido por "arte», a partir de la traducción latina ars, pero hoy en día esa versión resulta del todo inexacta. Los estudiosos contemporáneos vierten el concepto griego por "ciencia", lo que es más apropiado ${ }^{32}$. Tanto Platón como Aristóteles ${ }^{33}$ definieron el vocablo de manera precisa dentro de la peculiar perspectiva de su pensamiento filosófico al que consideraban la única ciencia con mayúscula. Para ello la téchnẽ más perfecta es la medicina, aunque hay también otras de menor rango como la pintura, escultura, retórica y la matemática ${ }^{34}$. Consiste en un saber organizado, eficaz, y, concretamente, el arte médico no es un mero resultado del empirismo sino que sus obras más destacadas hacen pensar en un verdadero espíritu cientifico.

En el siglo $\mathrm{V}$, especialmente en sus últimas décadas, van naciendo diversas téchnai: retórica, medicina, culinaria, etc. La téchnẽ se diferencia de la experiencia (empeiria) en que ésta conoce los hechos, dispone de un buen número de datos, pero no sabe explicarlos, no se para a pensar por qué acaecen asi. En cambio, la téchnē, especialmente, la medicina, se preocupa por saber las normas y causas, $y$, asimismo, por poder transmitirlas y enseñarlas a otros. El médico hipocrático proclama, una y otra vez, que es un "artesano" (technitẽs) de la medicina; que sabe manejar las manos y usar la inteligencia al tiempo. En tal sentido la «ciencia médica» sirve para librarse del azar, para conocer y preveer lo que ha de acontecer. Tal téchnẽ recibe a veces en los tratados médicos el título de sophia «sabiduria», e incluso, en dos ocasiones muy debatidas, el de epistẽme, "ciencia pura".

31 Aitia, aitios, aparecen alli en cap. 1 (9 veces); 6; 20 (3). Próphasis, 1 (3); 5; 13 (2); $18 ; 21$. Phisis, 1; 4 (3); 14; 16 (2);20;21.

32 Cf. Hippocratic writings, ed. G. E. R. Lloyd, Aylesbury, 1978, entre otros.

33 Gorgias, 450 c y Fedro, 271 c; Metafisica, 981 b 23-24 respectivamente.

34 Cf. Bourgey, Observation... págs. 231 y ss. 
«El arte de la medicina es el más ilustre de todas las artes...» ${ }^{35}$. El objetivo de ese arte ues apartar por completo los padecimientos de los que están enfermos y mitigar los rigores de sus enfermedades, y el no tratar a los ya dominados por las enfermedades, conscientes de que en tales casos no tiene poder la medicina ${ }^{36}$. "La ciencia considera oportuno intentar la cura después de informarse, examinando cómo curará, no con audacia, sino con entendimiento»" ${ }^{37}$. "La medicina hace tiempo que tiene todo lo que necesita para ser una ciencia y ha descubierto un punto de partida y un método» ${ }^{38}$.

8. Vamos a examinar ahora otras teorias y conceptos médicos relevantes de la medicina hipocrática, origen de la medicina científica europea.

a) En buena parte de los tratados hipocráticos se nos habla de la presencia de humores en el interior de nuestro cuerpo. Los humores son considerados a manera de elementos secundarios que se mueven con más o menos facilidad y se mezclan frecuentemente entre sí. Tal teoría, que propugna la existencia de hasta cuatro humores (bilis amarilla, bilis negra ${ }^{34}$, flema y sangre) y que no está muy alejada de la cuidadosa observación de las heridas, toda vez que la sangre brota roja, al principio, para perder luego color y terminar por adquirir un tinte ligeramente amarillento, está en intima relación con las cuatro propiedades de los cuatro elementos, tal como venían siendo formulados por lo filósofos presocráticos: frio/caliente, húmedo/seco, dentro de una distribución adecuada al pensamiento arcaico, o sea, a la oposición polar, o radical, de contrarios.

La flema, por ejemplo, suele compararse con lo frío, mientras que a la bilis se la considera caliente. Hay individuos flemáticos, biliosos, sanguíneos, según el humor que en ellos predomina. Aparte una estrecha relación entre individuos y condiciones ambientales: frio, calor, sequedad, humedad, aguas, vientos, etc., y entre las enfermedades y las estaciones del año ${ }^{40}$.

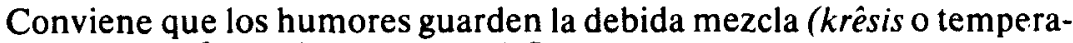
mento), para disfrutar de buena salud. Si los humores, bien sean cuatro, tres o dos, no se mezclan bien, ya a causa de una enfermedad que los altera, ya de resultas del predominio de un humor sobre los demás (monarchiẽ), una vez roto el equilibrio mutuo (isonomiê), sobreviene la intemperancia o falta de mezcla oportuna, y surgen los desarreglos y enfermedades, tal como el

35 Ley 1.

36 Sobre la ciencia médica, 3.

37 Sobre la ciencia médica, 11.

38 Sobre la ciencia médica, 2.

39 O atrabilis. En nuestra lengua "atrabiliario», "melancólico" son términos derivados de tal concepto.

${ }_{40}$ Es la idea general de Sobre los aires, aguas y lugares, Cf. lo que deciamos en Epos, 1 , 1984, págs. 103-118. 
avisado médico hipocrático observaba en las evacuaciones corporales, líquidas y sólidas. Cuando hay intemperancia (akrasiê), la mezcla adecuada puede conseguirse mediante la cocción (pépsis), a fin de que humor crudo (omós) pase a estar cocido o puro (katharós).

Con respecto a la sangre $e^{41}$, un humor como hemos visto, el hipocrático tiene curiosas teorías: la sangre sufre alteraciones en cantidad y calidad, según las estaciones, el sexo y la edad; es húmeda y caliente, con lo que viene a quedar claro el postulado de que el vino sirve para aumentar la cantidad de la misma. La sangre reparte el alimento por todo el cuerpo; el alimento ingerido se transforma en sangre en el vientre, $y$, desde alli es repartido por el cuerpo.

El hipocrático, empero, no distingue entre venas y arterias; se nos habla de un gran vaso situado a la derecha del cuerpo (la vena cava), y de otro, a la izquierda, que sirve para mantener en suspenso el corazón. Precisamente, el vocablo "aorta» (aortê $)^{42}$ quiere decir «que mantiene en alto, en vilo». En cuanto al término «arteria» (arteriē), que también alude a la acción de sostener en vilo, tiene un valor polisémico y se aplica tanto a la tráquea como a la aorta. Por cierto, en el sentir del médico hipocrático, la tráquea sirve para mantener suspendido el pulmón, que, curiosamente, siempre aparece en singular en los escritos hipocráticos. Hemos de esperar hasta Praxágoras, a fines del siglo IV a. C., para hallar una clara diferenciación entre venas (para él, llenas de aire) y arterias (repletas de sangre). Naturalmente, conocer la circulación de la sangre quedaba demasiado lejos de unos hombres como los hipocráticos, a quienes estaba prohibido la disección anatómica por una ley general.

Ya que venimos hablando de venas y arterias, añadamos algo a propósito del corazón. En el tratado titulado Sobre el corazón, evidentemente tardio pues encontramos en él ciertas teorías de Aristóteles (384-332 a. C.), se nos dice que el corazón es un músculo y que está rodeado de líquido; se nos habla de las válvulas sigmoideas y las auriculas ventriculares y se afirma que la inteligencia humana reside en el ventrículo izquierdo, en donde precisamente no hay sangre, según el autor del curioso escrito.

b) La idea de que hombre está inmerso en su medio ambiente y es una pieza más dentro del enorme espacio cósmico que lo rodea se manifiesta de modo singular en la teoría del pneuma (pneûma), tal como aparece recogida en varios escritos hipocráticos. El pneuma, nos dice el autor de Sobre los flatos, se llama "aire» (aẽr) cuando está fuera del cuerpo, y «flato" ( $p h \hat{y} s a$ ), cuando se encuentra dentro del mismo. La misión más relevante del pneuma dentro del cuerpo humano es alimentar, impulsar y refrescar.

El aire a juicio de los hipocráticos, penetra en el interior de nuestro cuerpo a través de la nariz y la boca, mas también por medio de los poros. La res-

${ }^{41} \mathrm{Cf}$. M. P. Duminil, Le sang, les vaisseaux, le coeur dans la Collection hippocratique, Anatomie et physiologie, Paris, 1983.

${ }^{42}$ Cf. el verbo aeirō "alzar en vilo», "sostener en alto». 
piración cutánea, en efecto, aparece formulada en varios tratados. En el cerebro, el pneuma es el encargado de producir la inteligencia, lo cual está en consonancia con las lucubraciones de ciertos presocráticos, para quienes el aire resultaba ser el elemento inteligente y conductor del universo. Posteriormente, el pneuma se mezcla con la sangre y pasa al pulmón y corazón. Mediante los vasos se difunde por todo el cuerpo, pero, si el pneuma queda detenido o entorpecido en algún punto del cuerpo, allí precisamente se produce el dolor y la enfermedad.

c) A propósito de la dieta (diaita quiere decir «régimen de vida») es posible que se remonten al propio Hipócrates algunos de los aforismos más famosos referentes a la necesidad de guardar una armonía entre los alimentos ingeridos y los ejercicios realizados. La dieta, en verdad, comprendía no sólo normas relativas a la alimentación (comidas y bebidas), sino también numerosas pautas respecto de ejercicios corporales, higiene general, horas de sueño y vigilia, etc.; todo ello de acuerdo con la edad, profesión, sexo, país, vientos, aguas, etc.

Era norma siempre mantenida por los hipocráticos el no excederse en el rigor dietético prescrito a los enfermos, lo que les valió, por cierto, las simpatías de numerosos comentaristas, pues, en palabras de Plinio el Viejo ${ }^{43}$, habia otras Escuelas médicas que "mataban de hambre» a sus pacientes.

Regla fundamental a la sazón practicada también por la Medicina posterior hasta hace relativamente poco tiempo, era la de no alimentar mucho a los enfermos en lo más intenso de las enfermedades, por pensar que, en tal momento, los alimentos acrecientan el vigor del mal. Claro está, había casos extremos en que casi se mataba de hambre al enfermo al someterlo a dieta rigurosa en enfermedades de larga duración ${ }^{44}$.

Mencionemos cierto punto interesante en un tiempo como el nuestro, en que tan de moda se han puesto los deportes personales y las dietas. Los atletas, a juicio de los hipocráticos, habian de seguir una dieta especial y estaban sometidos a rigurosos regímenes y normas estrictas. Los primeros aforismos ${ }^{45}$ nos ponen al tanto de muchos de esos curiosos aspectos y detalles.

La idea central que guiaba a los hipocráticos en este terreno es que, cuando los alimentos prevalecen sobre los ejercicios, se produce plétora (plẽsmónẽ), mientras, que, si los ejercicios son demasiado intensos respecto a la alimentación tomada, sobreviene vacuidad (kénõsis). En ambos casos surgían enfermedades de varios tipos. Cuando se producía plétora, los médicos aconsejaban toda una serie de vaciamientos a fuerza de purgantes $y$ sangrías.

d) A su vez, el pronóstico (prognõstikón) es un elemento clave en la actuación médica. El hipocrático, sirviéndose de los signos externos de la en-

${ }^{43}$ Historia Natural, XXII, 136.

44 Aforismos, I, 4.

45 Aforismos, I, 3. 
fermedad (sédmeîa, tekmēria), de la observación cuidadosa del cuerpo y constitución del enfermo, y también de las circunstancias ambientales y astronómicas (estaciones del año, momento de la salida o puesta de ciertas constelaciones) podía, sabía y quería ganarse la admiración, el aplauso y el reconocimiento monetario de parte de sus clientes, al manifestar, a la vista de un paciente concreto, qué le había acontecido antes a éste y qué le sobrevendría después. Esto es, en resumidas cuentas, el pronóstico.

Realmente, el pronóstico consiste en un preconocer más que en un predecir. Es una especie de sintesis del pasado (partiendo de la información suministrada por el enfermo), del presente y del futuro. El diagnóstico, en cambio, sólo mira a los síntomas presentes. Pues bien, el buen médico, el que despertaba la admiración de todos los que presenciaban su actuación, era el que sólo con mirar, tocar, oler y pulsar al enfermo, a la vista de la ciudad en que éste vivía y de las circunstancias ambientales que le rodeaban, sabía decir lo que le había acaecido, lo que entonces le pasaba y lo que le ocurriría más tarde. Precisamente, el Pronóstico es uno de los escritos atribuidos a Hipócrates por casi todos los estudiosos.

e) La crisis (krisis) es un concepto central sobre el curso y solución de la enfermedad. La crisis es el momento preciso en que la enfermedad se decide $^{46}$, se resuelve y se encamina hacia la definitiva solución, 0 , por el contrario, provoca la muerte del enfermo. La crisis se presenta acompañada de una serie de signos externos bien conocidos por el buen artesano de la medicina. Entre los «signos críticos» están: la orina, sudor, heces fecales, esputos, vómitos, etc. Por ejemplo, un aforismo nos dice: «los sudores fríos, cuando se producen con fiebre aguda, indican la muerte; con fiebre más moderada, la duración de la enfermedad $)^{47}$.

Durante la crisis, como va acompañada de la cocción de la enfermedaad, no conviene molestar al cuerpo de modo alguno, ni tampoco administrarle purgantes, a fin de que mantenga su propio calor. Un aforismo reza asi: «a los que sufren una crisis, o acaban de sufrirla, no se les mueva, ni se haga experimentos con ellos, ni con purgantes ni con otras sustancias irritantes, sino déjeseles en paz» ${ }^{48}$.

9. A modo de paréntesis mencionemos la ética médica de los hipocráticos. Para ello conviene recordar que en todo el periodo clásico griego la esclavitud fue una innegable realidad ${ }^{49}$. En Atenas, por citar un caso notable, no más de la cuarta parte de la población eran hombres libres. Dicho esto,

46 Krisis quiere decir en griego «juicio», "sentencia», "resolución».

47 Aforismos, IV, 37.

48 Aforismos, 1, 20.

49 Ha sido un tema bien estudiado en todo el mundo antiguo desde 1950. Destaca el trabajo de F. Kudlien, Die Sklaven in dergriechischen Medizin der Klassischen und hellenistischen Zeit, Wiesbaden. 1968. 
podemos entender mejor que, a la razón hubiera dos clases de médicos ${ }^{50}$ : los de gentes libres, que hablaban a sus pacientes, les explicaban detalles diversos acerca de la afección que les afligía, les daban normas dietéticas, los trataban con afecto e, incluso, les enseñaban puntos concretos del saber médico ${ }^{51}$; los médicos de esclavos, que, al decir de Platón, los trataban como tiranos sin intercambiar con ellos ni una palabra.

El médico normal de que nos hablan los escritos hipocráticos visita a sus enfermos o tiene una pequeña consulta adonde acuden los pacientes. Una nota común en tales médicos, a diferencia de lo que venía sucediendo hasta entonces, es la elevada conciencia sobre su dignidad profesional, a la que aluden repetidas veces los tratados que más de lleno tocan estas cuestiones. Ahora bien, no debemos confundir a los médicos normales de la época que estudiamos -fines del siglo $\mathrm{V}$ y mediados del $\mathrm{IV}$ - con los autores de los escritos hipocráticos, hombres bastante cultos, refinados y de un nivel superior al habitual en los médicos de cada día.

En los Preceptos escrito tardio (siglo I o Il a. C.), pero de notable influencia en la posteridad, se aconseja a los médicos que no piensen lo primero en el dinero, sino en curar a los enfermos; que no deben discutir con el paciente sobre lo que se le va a cobrar, pues eso sería agravar la enfermedad; que practiquen, a veces, la medicina de forma gratuita, acordándose de algún favor recibido o mirando al simple prestigio personal; si llegare la ocasión de atender a quien es extranjero o pobre, que ayuden sobre todo a los de tal condición, pues si hay amor a la humanidad (philantröpiē) hay también amor a la ciencia (philotechniê $)^{52}$.

De la elevada conciencia profesional de los médicos hipocráticos nos da cumplida noticia el Juramento, fechable a comienzo del siglo IV a. C. En tal escrito el médico se compromete a enseñar gratis a los hijos de su maestro y a tratar a éste como si fuera su padre; a no dar medicinas mortales ni aunque se las pidan; a no proporcionar pesarios abortivos; a no operar a quienes padecen de litiasis; a no tener contacto sexual en las casas donde entrare, ni con mujeres ni con varones. A su vez, en Sobre el médico hallamos sabias admoniciones dirigidas a los médicos en relación al atuendo, perfumes apropiados, actitud callada y prudente, limpieza de manos y cara, etc.

Todo lo dicho nos ilustra acerca de la profunda apreciación sobre su propia profesión entre los médicos más selectos de la Colección hipocrática. Bien es cierto que no todos pensaban igual, ni mucho menos, pero en general, en los escritos que nos han llegado late un profundo respecto, una dignificación consciente y responsable a propósito de la ciencia que practicaban,

50 Platón, Leyes, 720, a-c.

51 Sobre la medicina hipocrática considerada como paideia, es decir, parte integrante de una cultura general, ha escrito hermosas y esclarecedoras palabras W. Jaeger, Paideia: los ideales de la cultura griega, trad. esp. México, 1968, págs. 783 y ss.

52 Preceptos, 7. 
y asimismo, acerca de la profesión médica y del trato y actitud que había que guardar ante el enfermo.

10. Podemos resumir de otra forma los rasgos esenciales que convierten en verdadera ciencia a la medicina, alejándola, al tiempo, de la magia y el puro empirismo ${ }^{53}$.

a) En primer lugar el aparecer como téchnẽ iatrikẽ, es decir, arte médica o arte de curar, con un fin propio y especifico expresado en numerosos pasajes: aliviar y curar a los enfermos y evitar la enfermedad. Tal ciencia sabe expresar qué hace y por qué lo hace. Para ello, el médico necesita poseer un conocimiento racional, científico diríamos con razón nosotros, de la causa por la que se ha producido una afección, y, asimismo, de los efectos que, llegado el caso, provocará el remedio que se prescriba al paciente.

b) En segundo lugar la convicción del médico en que radica en la naturaleza la causa de la enfermedad y la virtud curativa del remedio. El enfermo, parte constitutiva de la natu raleza, está regido por unas normas concretas, precisas, consabidas. La enfermedad está presidida por unas leyes racionales; por ello, no hay que acudir a expedientes irracionales para curarla.

Los fármacos (especialmente, eléboro negro, agua de nísperos, comino, anís, vino), sustancias externas capaces de provocar cambios favorables 0 desfavorables en el enfermo, poseen un poder curativo en virtud de sus propiedades saladas, amargas, astringentes, laxantes, eméticas, etc. El fármaco sirve, asimismo, para purgar o purificar (kathairein) en forma de eméticos, purgantes o diuréticos.

La práctica quirúrgica, tan desarrollada en tratados como Sobre las fracturas y Sobre las articulaciones, muestra a la claras que el cauto médico hipocrático acude primero a los sentidos (toca, piensa, razona, recuerda) y, por último, actúa. La importancia decisiva de la vista y la mano en el actuar médico resulta conspicua en los escritos antes mencionados.

c) En tercer lugar, como consejo y resumen, leemos en el último aforismo: «lo que los medicamentos no curan, el hierro lo cura; lo que el hierro no cura, el fuego lo cura. Pero lo que el fuego no cura, eso es preciso considerarlo incurable ${ }^{54}$. Con ello queda medianamente expresado el convencimiento de los hipocráticos en las limitaciones curativas de su ciencia.

d) En cuarto lugar, la enfermedad viene a ser una alteración del equilibrio de la naturaleza, de la salud, en suma. Tal desarreglo se llamará «intemperancia» (dyskrasiê), "predominio de un humor sobre los otros" (mo-

${ }^{53} \mathrm{Cf}$. al respecto P. Laín Entralgo, La medicina hipocrática..., págs. 423 y ss.

54 Aforismos, VIII, 87. 
narchiê), dificultades en la fluidez de los humores por el cuerpo (dýsroia), etcétera.

11. Desde siempre, cualquier rama científica, o que aspira a serlo, ha sentido la necesidad primordial de crear un lenguaje especializado que la defina respecto de los demás saberes de su época. Es, en resumidas cuentas, la Fachsprache o lengua de las profesiones especializadas. Tal tendencia resulta especialmente visible en el caso de la Medicina hipocrática, que surge espectacularmente ante nosotros con unos tratados bien construidos literariamente y con un contenido totalmente distinto del correspondiente a las prácticas supersticiosas de la medicina mágica anterior o coetánea.

Las vías seguidas por los médicos hipocráticos a fin de crear una lengua especializada nos son relativamente bien conocidas: recursos morfológicos (derivación abundantísima, delimitación de sustantivos mediante adjetivos); léxicos y metafóricos. Pues bien, aunque no contamos todavía con un léxico apropiado de toda la Colección hipocrática, podemos ver que los nombres de las enfermedades apuntan al lugar en donde se producen (ophthalmie, peripleumoniē, arthritis, dysenterie); a su color (alphoi, erysipelas...), al aspecto del cuerpo (lépre, leichẽn, phlegmónè, exantẽmata...); a su origen (hélkõsis, lipopsychiẽ, paraphrosýnẽ...); a características varias (strangourie, kynánchai...).

Examinando, recientemente, el léxico de los Aforismos reparamos en que hay bastantes términos que ofrecen muchos problemas de comprensión y, naturalmente, de versión a nuestras lenguas modernas ${ }^{55}$. Gran parte de las dificultades surge en vocablos referentes a la anatomia humana o a funciones muy relacionadas con ella. Así sucede con koilie, splánchna, kineîn, kathairein, etc. Otros problemas acontecen en campos semánticos que se están constituyendo en el momento de ser escritos los tratados hipocráticos y todavía no aparecen bien establecidos.

12. Pues bien, para finalizar, añadamos que la Medicina hipocrátlca ha experimentado un notable resurgimiento en las últimas décadas, tal como demuestran los cinco Coloquios internacionales a ella dedicados en los últimos años ${ }^{56}$. Es un campo extraordinariamente fecundo donde confluyen armoniosamente los esfuerzos de filólogos clásicos, historiadores de la Me-

55 "Sobre el léxico de los Aforismos hipocráticos», en Apophoreta Philologica, homenaje a M. Fernández Galiano, Estudios clásicos, 87, 1984, págs. 91-96.

56 La Collection hippocratique, cf. nota 19. Corpus Hippocraticum, Actes du Colloque hippocratique de Mons (sep. 1975), Mons, 1977. Hippocratica, Actes colloque hippocratique de Paris (sep. 1978), Paris, 1980. Formes de pensée dans la collection hippocratique, Actes IV Colloque inter. hippocratique Lausanne, 1981), Ginebra, 1983. 
dicina, médicos, filósofos y otros estudiosos de la antigüedad, sin olvidarnos de los que han seguido las huellas de la medicina a lo largo de los siglos en sus diferentes aspectos: transmisión, códices, traducciones, comentarios, etc. Efectivamente, en esos Coloquios hipocráticos se ha visto la enorme influencia que los escritos hipocráticos han tenido en la Historia del pensamiento y en la práctica médica desde la antigüedad hasta nuestros dias. Si bien no faltan en tales obras aspectos arcaicos, es lo cierto que la Medicina hipocrática, al ser comparada con otras medicinas antiguas como la india, china o egipcia, resulta mucho más avanzada, pues alcanzó una gran independencia respecto de la magia y la religión, librándose de prácticas mágicas y de exorcismos, y sentando las bases racionales de una verdadera ciencia. 